\section{Enjoy a new perspective of the Earth}

\section{Earth scientist and remote- sensing expert Shannon Franks describes how there is more to NASA than space exploration}

When people think of NASA, the first thing that comes to mind is probably an image of astronauts floating around the International Space Station, or perhaps the great discoveries that have come from the agency's space programme. However, while space exploration and rocket science are among NASA's better-known achievements, it also does cutting-edge Earth science, forging new ways to monitor the planet we call home.

I work as a contractor at NASA's Goddard Space Flight Center (GSFC) in Greenbelt, Maryland, and my research is on Earth observation. Specifically, I use the techniques of remote sensing to process and analyse images that have been collected by Earth-orbiting satellites. The term "remote sensing" describes the acquisition of information about an object or phenomenon without actually being in contact with it, so in some ways, we are all doing remote sensing every time we use a camera. However, when used scientifically, remote sensing also involves harnessing parts of the electromagnetic spectrum that are not otherwise visible to the human eye. For example, when using infrared light, the vitality of vegetation becomes more apparent and its level of moisture is more visible.

\section{Clarity through elimination}

When I started my undergraduate studies at Northland College, Wisconsin, I followed my passion for the outdoors and the natural environment by pursuing a degree in environmental science. I was living in a small town, surrounded by all the nature I wanted, and everything was bliss. I envisioned a career with the Environmental Protection Agency, studying streams or perhaps working on some other project that would let me

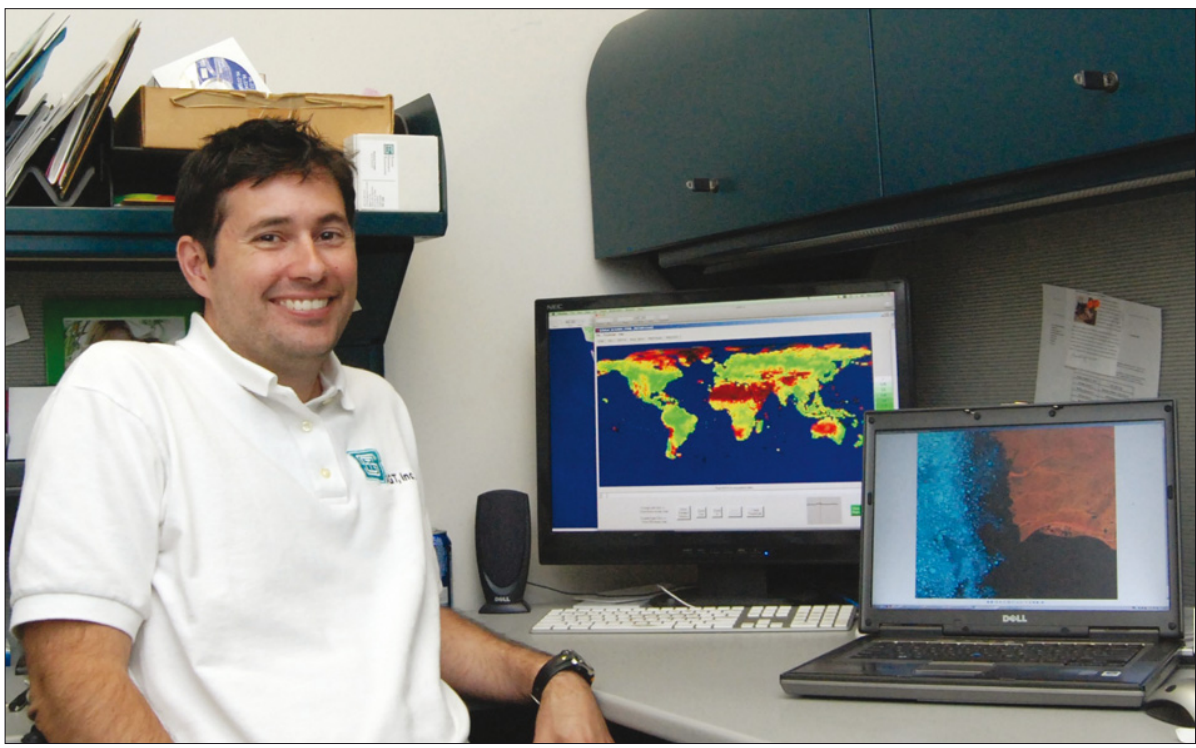

Homing in on home Shannon Franks uses satellite images to study the Earth.

care for the health of the environment.

Not everything, however, was so easy. During my first year, I was in a car accident that left me paraplegic and confined to a wheelchair. My dreams of working in the field doing studies in the outdoors virtually vanished at that instant. But although I could no longer easily access the remote wilderness areas that interested me, as I once did so effortlessly, none of this worried or deterred me from having a clear idea of what I wanted in life. I just had to make an adjustment. My mind was as strong as ever and my determination to reach my goals was even greater.

After rehabilitation, I returned to my studies. As I settled into the groove of university education, I found that I enjoyed higherlevel mathematics and physics, too, so I decided to take the required courses for a degree in physics as well as environmental science. As my skills and interests became clearer, I realized that I faced a dilemma: how could I combine my passion for the environment and my interest in physics into a career? The light bulb in my head lit up as soon as I took a physics course on environmental modelling. This course introduced me to the concept of remote sensing, and I was immediately hooked.

The thing that eventually paved the way to my career in remote sensing was a series of summer internships. I did internships every summer during my undergraduate years, and this not only gave me a chance to travel around the US - something I love doing but also allowed me to apply my skills in different career environments. During the summer of 2000 I did an internship at the GSFC's Landsat Project Science Office, where I learned the specifics of satellite imagery and its many applications to society.
It was a great project to work on; not only does Landsat have the longest continuous record of satellite land-surface observation but, at the time of my internship, the programme had just launched its most recent and advanced satellite to date (Landsat 7). I was amazed by the work done there and the amount of information that can be derived from those beautiful images of Earth's surface. For example, what some people might consider a pretty picture of the coral reefs in the Florida Keys, scientists consider critical data for mapping coral-reef degradation caused by pollution. A picture really can be worth a thousand words.

\section{Data integration}

A few years after my first encounter with NASA's remote-sensing studies, I earned a Master's degree in geography from the University of Maryland, and this led me to my current job. For eight years I have been working at NASA as a contractor, of which the past three years have been as an employee of a firm called Stinger Ghaffarian Technologies (SGT). At the GSFC, roughly $50 \%$ of the workforce are contractors and there are many great relationships between the civil servants and the contract employees. SGT is one of those contracting companies and it has really provided me with the support and freedom to grow.

When I was an intern at the GSFC, I was making pictures and posters of satellite imagery purely for aesthetics, but now I make them to portray my research and its results. During my career, I have worked on numerous Earth-science projects, from studying vegetation regrowth following large-scale fires in Yellowstone National Park, to creating global datasets, and I am currently help- 
ing my NASA colleagues test a prototype method of estimating global carbon stocks at hectare-scale $\left(10000 \mathrm{~m}^{2}\right)$ resolution. By integrating many sources of information, such as land-cover data from the Landsat satellite, tree-canopy information from lidar sources (pulses of light directed towards the ground and returned to map surface heights), and radar- and ground-collected field data, we are developing the most accurate way to date of predicting global carbon stocks and fluxes of forests. Since understanding the global carbon cycle is essential for predicting climate change, having this information about biomass flux is crucial.

On a daily basis, I am applying principles of physics and mathematics to analyse information from satellite imagery. One thing you quickly learn in this field is that while remotely sensed Earth imagery is visually impressive, behind every pretty picture there is information in the form of pixel values, and these have to be interpreted. For example, the data are often a stream of values from zero to 255 (calibrated to the reflected and emitted energy received at the satellite, in the case of Landsat), so I have to be able to interpret how the changes in those values relate to changes in Earth's land cover. I also use an advanced algorithm to help me find the best satellite images to use in analysing the way that land cover has changed. In a position such as mine, there are two things that you need: the curiosity to ask questions; and the willingness and skills to find the answer to those questions. Without my background in physics, that would not be possible.

I often get asked how a person gets a job at NASA. The first thing I usually tell them is that it is not easy. NASA is continually ranked as one the best federal institutions to work at thanks to its culture and benefits, so there is not a high turnover of staff - people tend to stay here for a long time, whether they are contractors or civil servants. So, on top of being highly qualified in whatever field you are in, I recommend that would-be applicants try to get a "foot in the door" in one way or another. For me, this was an internship, but many people get hired because they made a good impression at a conference or have been recommended by another employee. As my experience shows, physics can lead to a fascinating career, and may even change your perspective of the Earth.

Shannon Franks is a remote-sensing scientist who works as an SGT contractor at NASA's Goddard Space Flight Center in Maryland, US, e-mail shannon.franks @nasa.gov

\section{Once a physicist: Hannu Rajaniemi}

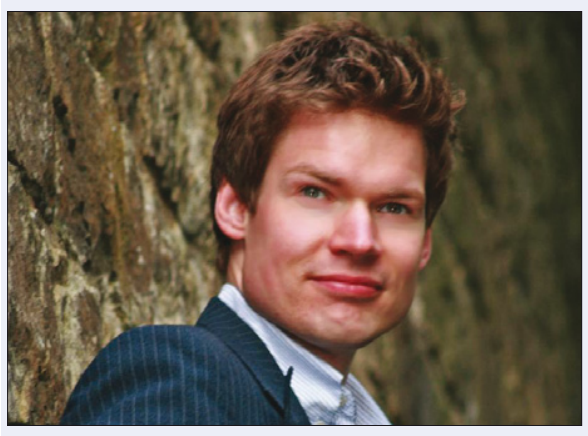

Hannu Rajaniemi is an Edinburgh-based sciencefiction writer whose first novel, The Quantum Thief, is published by Gollancz in paperback this month

\section{What sparked your interest in physics?} From quite early on, I had this sense of wonder at the fact that there seems to be some sort of underlying mathematical structure that the universe obeys, and we are able to access it. This is a very counterintuitive thing: humans evolved as huntergatherers on the savannah, yet we have been able to develop this abstract language that says some very deep things about how the universe works. I was a big fan of Jules Verne and a book called Our Friend, the Atom, which is a history of atomic physics done in a very 1950s "techno-optimistic" style. I started out studying theoretical physics at the University of Oulu, Finland, but ended up getting my degree in pure mathematics. Then I did part III of the mathematical tripos at Cambridge, followed by a $\mathrm{PhD}$ at the University of Edinburgh that combined mathematics and physics. I consider myself more of a mathematician than a physicist, although my research was in string theory, which mingles the two.

What inspired you to write science fiction? I have always been a science-fiction reader, and I had various creative pursuits at university, including playing table-top role-playing games. But when I came to the UK, I lost touch with the people I was doing that with, so writing became an attempt to find an alternative outlet for my creative impulses. One thing that really helped was that I joined a writers' group in Edinburgh that included some well-established professional members, and they encouraged me to believe that I could write and be published.

\section{How does science enter your writing?} My first novel is called The Quantum Thief, and it grew out of this idea I had of writing a sort of "heist" story set in a very distant, technically advanced future. On reflection, I decided that this idea posed some problems, because if you think about the implications that technology would have on future societies, one thing that comes to mind is that advances might lead to a "post-scarcity" situation in which material goods no longer have any value. So what would people have that was worth stealing? There might be some intangible things such as identity or reputation that would have value, but they did not seem all that interesting to me. Then I realized that one strong element in this future world would be quantum information, and in quantum mechanics there is something called the "no-clone theorem" that says you cannot copy, or clone, a quantum state. So I came up with the idea that in this future world, there might be a "quantum thief" who would steal actual quantum states that had some intrinsic value.

\section{What are your other influences?}

I have quite a fondness for 19th-century authors of science fiction and detective stories - people such as Maurice Leblanc and Arthur Conan Doyle - and I also admire some more contemporary writers including Roger Zelazny and lan McDonald. Another influence is Geoff Manaugh whose blog about architecture, BLDGBLOG, features some strange and bizarre architectural ideas such as walking cities. I got an idea from there about "memory castles", which is the ancient technique of structuring your thoughts in terms of imagined or real spaces, with objects in those spaces acting as mnemonic devices. The other writers in the Edinburgh group also really helped me develop my craft. A writer is always a bit like a magpie - you collect things from all over.

\section{What are you working on now?}

My next novel, The Fractal Prince, will be a sequel to The Quantum Thief, and it will take some of the characters in the first book and add new themes and characters to the mix. Whereas The Quantum Thief is about privacy and how memories shape identities, the new book will be more concerned with how consciousness and the nature of stories could change in a future where our minds are digitally malleable. I am also a co-founder of a private mathematical research firm, ThinkTank Maths, so in that sense I am still very much involved in science, though more on the leadership side.

Do you have any advice for current physics students with an interest in writing? Read widely - not just in physics but also philosophy, history, world literature - and develop interests that allow you to see physics in a wider context, rather than as just an isolated subject. I think writing is very much about developing some kind of world view that you want to communicate, so it is good to see the big picture.

\section{brightrecruits.com}

To make the most of your physics degree, visit www.brightrecruits.com 